\title{
Recognition and Analysis of Poor Students on College Students Campus Card Consumption Data Based on Big Data
}

\author{
Aifeng $\mathrm{Li}^{\mathrm{a}}$, Zhineng Xiaob ${ }^{\mathrm{b}}$, Biyun Liang ${ }^{\mathrm{c}}$ \\ Network and Modern Education Technique Center, Guangzhou University, Guangzhou 510006, \\ China \\ aLiaf0210@gzhu.edu.cn, bxzn21cn@gzhu.edu.cn,' ${ }^{\circ}$ lbiyun@gzhu.edu.cn
}

Keywords: Big data, Campus card, Poor student recognition, Consumption data.

\begin{abstract}
Subsidization for students from low-income families is a major student management work for colleges and universities. With deep and extensive use of big data in all sectors, relevant big data shall be used to identify poor students. Using big data rationally for targeted subsidization represents in-depth application of big data in educational field. In this thesis, the researchers collected 36546 data concerning dining consumption of students in three months, used Datist, a big data analysis software to build a model, acquired concerning dining habits, consuming behaviors, situations in school and consumption indicators of the students, and then selected poor students. This study laid a solid foundation for large-scale dynamic implementation of "campus big data and targeted subsidization", accurate recognition of poor students and rational student analysis in future.
\end{abstract}

\section{Introduction}

As we know, recognition of poor students is a tedious but important work in colleges. The accuracy directly influences effect and efficiency of subsidization for poor students. How to make "targeted subsidization" is one of the top concerns of school leaders and relevant authorities. We have adopted many measures in the past many years, but the results are not satisfactory. Accurate recognition of poor students is still a difficult problem.

In order to identify poor students accurately and know about living conditions of students in campus, we collected 34654 records concerning dining consumption of 118 students from School of Mechanical and Electric Engineering (SMEE) of our university from September 2012 to December 2012. After analyzing the data with "Datist", a big data analysis software independently developed by Digital Oilfield Institute of Chang'an University (Big Data Research \& Development Center of Chang'an University), the researchers preliminarily obtained the dining habits, consuming behaviors, situations in school and consumption indicators of the 118 students, and then selected poor students, which laid a solid foundation for large-scale dynamic implementation of "campus big data and targeted subsidization", accurate recognition of poor students and rational student analysis in future.

\section{Students' Consumption Data Modeling}

After making normalized processing of students' basic information and dining transaction data (information of gender and native place shown on students' ID cards and dining dates according to the dining transaction records), we set up a data model after adding information concerning meal and dining week.

\section{Analysis on Students' Dining Consumption Information}

After modeling, we analyzed dining data of the 118 students from September 9 to December 28, 2012 (111 days in total) and acquired information of the students' dining habits. 


\subsection{Analysis of expenditure}

According to each consumption of the students, the maximum amount is RMB 177.2 and the minimum amount is RMB 0.1 (average: RMB 4.28). The major distribution interval is from RMB 1 to RMB 6. It shows that price distribution of the school canteen is reasonable.

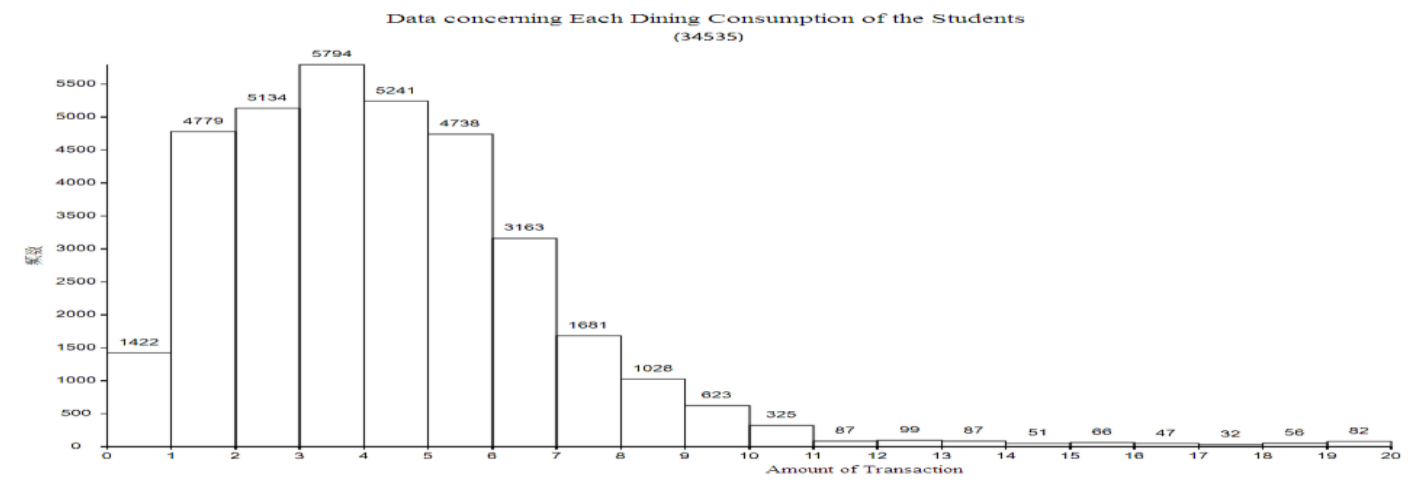

Fig.1:Data concerning Each Dining Consumption

From each dining consumption of the students, consumption for breakfast is lower than that for lunch and dinner. It conforms to people's living habit. The following chart is an analysis on dining consumption situation of the students in the three months. The total consumption of most students in the three months is lower than RMB 2000. Some students consumed RMB 2000-3600 on dining in that period.

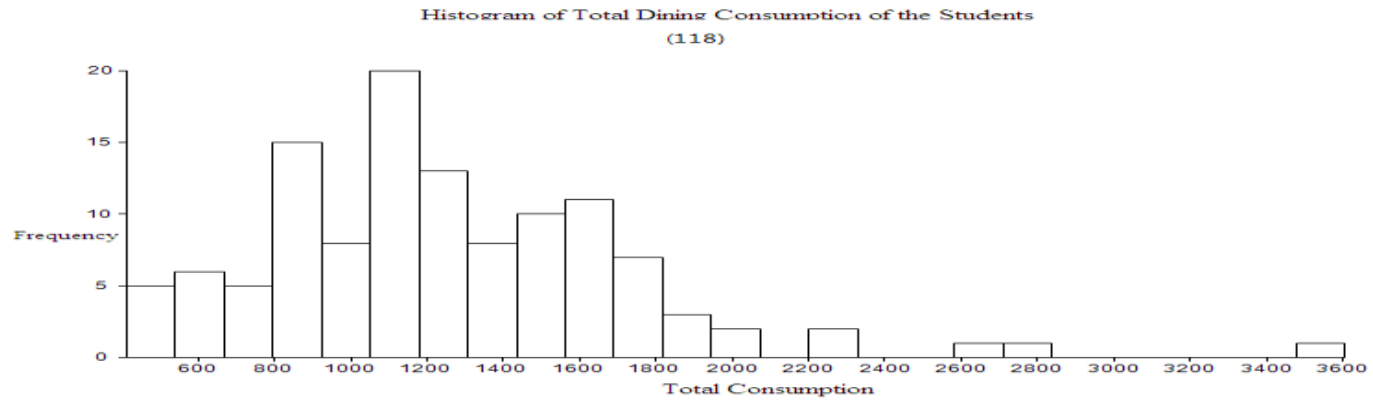

Fig.2:Total Dining Consumption of the students

\subsection{Dining habit analysis}

The following chart shows total number of meals taken by the students each day in the three months. From the histogram, it can be seen that most students have 2-3 meals each day; not many students take breakfast; and a small number of students have extra meals.

\section{Analysis on Abnormalities with Students' Consumptions}

The following analysis is about abnormal situations found in the dining data of 118 students within the three months from September to December 2012.

\subsection{Analysis on students without dining consumption records for at least 7 days}

The following table shows students who have no dining consumption records for at least 7 days in succession within the three months. There're 113 students in total. Due to limited space, we listed 7 students.

\subsection{Record of large expenses on dining}

The students' expenses on dining exceeding RMB 30 may be other consumptions in campus, such as supermarket consumption, Internet fee or hospital charges. If the records are hospital charges, the researchers would pay special attention to these students. 
Table 1. No dining consumption records for at least 7 days

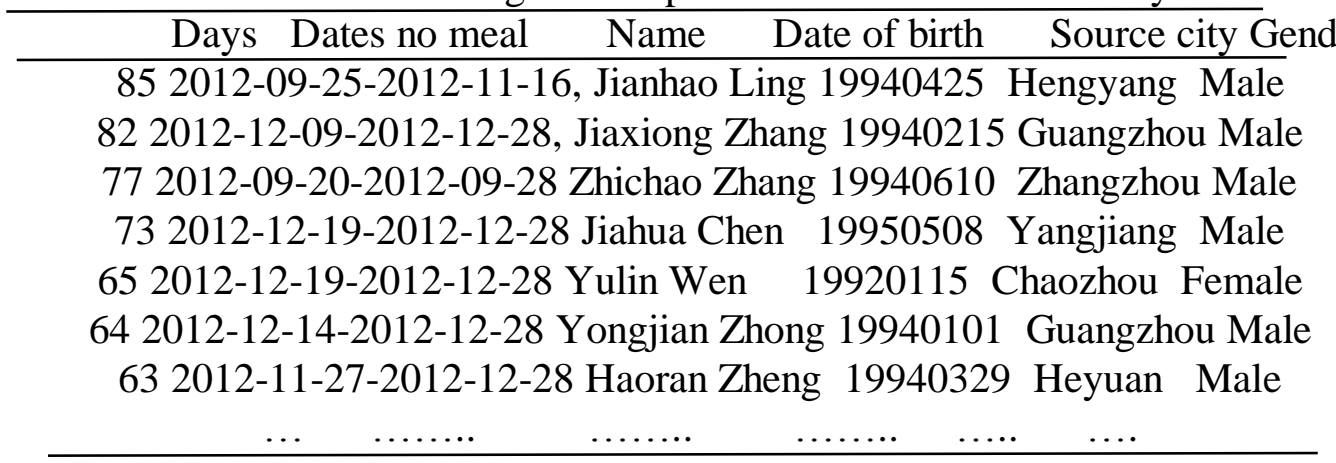

\section{Conclusions and Suggestions}

\subsection{Conclusions}

In this study,by analyzing the dining data,we realized two points. First, we analyzed the living conditions of students and knew about their dining habits and consumption indexes. Second, depending on systematic campus big data, targeted subsidization can be realized. That's to say, with big data, the school can find non-impoverished students among students who have been subsidized, and those who are actually in need but do not want to tell.

\subsection{Suggestions}

From the above analysis result, it can be seen that "Campus Card" transaction records can help us to distinguish poverty degrees of students and can be used as a criterion of subsidization. In order to make accurate recognition of poor students, we have the following suggestions.

1) This big data analysis is a school-wide experimental study. "Campus Card" consumption data of only 118 students in 3 months are far from enough. In future, they are going to make a comprehensive analysis of all students in a school year in order to get a more accurate result.After acquiring the "Campus Card" transaction records of all students, we can compare poor students with the non-impoverished ones, and then better learn the living conditions of the poor students. Moreover, we find those who are actually in need but did not declare for subsidization. By acquiring more detailed transaction data of "Campus Cards", such as charging data and swiping terminal information, the transaction types can be better identified, and non-dining transactions can be removed.

In future study, RFM model can be improved depending on the students' consumption behaviors. Machine learning classification modeling can be made by using the name list of poor students; and network relations modeling can be made depending on the dining sequence of the students.

2) In future, data of the educational administration system can be acquired, and a comprehensive analysis can be made together with the learning situations of poor students. Thus, limited fund can be used to subsidize those poor students who have good academic performances.

\section{Acknowledgments}

This work was supported in part by the Guangzhou education science planning project of 2016 (1201534833).

\section{References}

[1]. Wang Jie. Study on College Library Information Service Platform based on User Behavior Data Analysis [J]. Modern Information, 2017(01):127-130

[2]. Chen Qinhua, Li Qiujie, Chen Li. An Empirical Study on the Relationship between Interaction Centrality and Interaction Quality on MOOCs Learners Forum [J]. China Educational Technology, 2016(02):58-63 
[3]. Liu Junhua. Information Regression, Distribution and Trend of Statistical Data Quality Evolvement in the View of Big Data [J]. Statistics \& Information Forum, 2015(9):7-11

[4]. Wei Shunping, Zhao Xuan, Cheng Gang. Study on Data-driven Online Study Presentation Model Building [J]. Journal of Tianjin Radio and Television University, 2015(3):35-41

[5]. Wang Miao, Liu Zhichao. Visualized Analysis and Case Study of Online Study Behaviors from Study Analysis Perspective [J]. China Education Info, 2015(9):10-13

[6]. Zhou Qingqing, She Hang, Ping Ping. Study on Building of Individualized Study Platform Model based on Big Data Evaluation [J]. China Education Info, 2016(15):13-15 